\title{
Still Waters Run Deep: Comparing Assertive and Suggestive Language in Water Conservation Campaigns
}

\author{
David Katz ${ }^{1, *(\mathbb{D})}$, Ann Kronrod ${ }^{2}$, Amir Grinstein ${ }^{3,4}$ and Udi Nisan 5 \\ Department of Geography \& Environmental Studies, University of Haifa, Haifa 39105, Israel \\ Manning School of Business, University of Massachusetts, Lowell, MA 01854, USA; ann_kronrod@uml.edu \\ D'Amore-McKim School of Business, Northeastern University, Boston, MA 02115, USA; a.grinstein@neu.edu \\ The School of Business and Economics, The Vrije Universiteit, 1081 HV Amsterdam, The Netherlands \\ 5 The Federmann School of Public Policy and Government, The Hebrew University of Jerusalem, Mt. Scopus, \\ Jerusalem 91905, Israel; udinisan@gmail.com \\ * Correspondence: katzd@geo.haifa.ac.il; Tel.: +972-4-8248-106
}

Received: 1 November 2017; Accepted: 22 February 2018; Published: 5 March 2018

\begin{abstract}
The current work focuses on non-price policies to achieve residential water conservation, specifically on water conservation campaigns. The authors report the results of a large-scale longitudinal field experiment encouraging residential water conservation among 1500 households. The effectiveness of two commonly-used message phrasings is compared: an assertive and a suggestive message. Assertive messages employ a commanding tone, such as "You must conserve water", whereas suggestive messages employ a more gentle approach, as in "Please consider conserving water". Despite the ubiquitous use of assertive phrasing in pro-social messages, and previous research that suggests that, in some cases, assertive language can increase message compliance, the authors show here that the suggestive, gentler, message language can make a more accentuated change in residential water conservation behavior. This may stem from the status of water as a basic needs resource, which may reduce the appropriateness of freedom restricting language, such as an assertive tone.
\end{abstract}

Keywords: demarketing; assertive language; water conservation; controlled field experiment

\section{Introduction}

Water conservation is an important goal in many countries around the world. Water managers and policy-makers have a wide range of policy tools available to attempt to implement demand management [1]. Public awareness campaigns have proven to be an increasingly popular means of encouraging environmental conservation, in general (e.g., [2-5]), and water conservation, in particular (e.g., [6-10]). Such conservation campaigns have various benefits over traditional market-based mechanisms, such as pricing, or command and control mechanisms, such as quotas or use restrictions. For example, public awareness campaigns are unlikely to face public resentment or opposition and can be implemented rather quickly.

In the marketing literature such efforts are often referred to as "demarketing", as they differ from traditional marketing in that they discourage rather than promote consumption [11]. In the context of water management, such demarketing efforts are often undertaken during periods of shortages together with numerous other policies to reduce consumption levels $[10,12]$. As such, it can be difficult to measure the policy's effectiveness [6,8]. Despite these challenges, there is increasing evidence that water conservation campaigns can be effective in changing consumer behavior, especially for short periods of time and with relatively low-cost $[9,13,14]$. 
While there is a growing body of literature on information and conservation campaigns as policy instruments for managing water demand, much less research has been dedicated to evaluating which types of interventions work best; this, despite the growing consensus in both the behavioral economics and marketing literatures that suggests that the content of conservation campaigns is critical to determining their level of effectiveness and to ensuring success, especially in the context of environmental management (e.g., [15-18]). Much of the existing work that has attempted to address the content of conservation messaging has focused on normative social comparisons, wherein an individual's or household's consumption is compared to that of their neighbors (e.g., [19-21])

Addressing the need for an effective communication strategy to encourage residential water conservation, this work investigates a different aspect of conservation messaging or demarketing, namely, the tone of the language used in conveying the messages. We report the results of a field experiment comparing two types of messaging languages: assertive and suggestive. Assertive language is defined as language that gives directions to the addressee without providing her/him an option to refuse [22]. For example, "Use less water!" or "You must use less water". Conversely, suggestive language offers the addressee freedom of choice. For example, "Please consider using less water".

In contrast to most consumer goods marketing messages, which were overwhelmingly found to use suggestive phrasing, the majority of environmental slogans were found to be assertive [18]. While much of the marketing and demarketing literature highlights drawbacks of assertive language in inducing compliance, some has demonstrated the effectiveness of assertive messaging in certain cases of pro-social communication, especially in environmental contexts $[16,18]$. However, some of the same literature has found that the different types of messages work differently for certain types of goods. Specifically, assertive messages were found to be more effective when relating to hedonic goods, while suggestive ones were more effective with utilitarian ones [22].

As water is a basic need, assertively encouraging water conservation may invoke resistance, as it may be perceived as a restriction of freedom. Therefore, assertively pushing the public to conserve water may not be as effective as a more gentle approach.

In this paper, we posit that suggestive messaging may be more effective in discouraging water consumption, compared with assertive messaging. Thus, while the effect of an assertive tone may be stronger in motivating other pro-social behaviors, such as recycling, a suggestive approach may be more appropriate in discouraging consumption of basic resources such as water.

To investigate this effect, we analyze the relative effectiveness of a demarketing campaign in a large-scale longitudinal controlled field experiment, in which we monitored actual daily water conservation behavior among 1500 households over a period of over six months in order to assess the effect of assertive versus suggestive demarketing messages. Using a difference-in-difference econometric model, we compared results from households receiving the two different demarketing messages to those from a control group receiving no message.

This paper contributes to longitudinal measurement of the effectiveness of non-price policies aimed at the reduction of residential water consumption. We conducted a longitudinal examination of the effectiveness of a real-world demarketing campaign and tested the time boundaries of its effectiveness. Further, this work distinguishes between types of pro-social communication and offers a counterargument for the use of assertive language, which is highly prevalent in pro-social communication.

\section{Literature Review}

\section{1. "Demarketing" as a Policy Instrument}

While marketing studies have traditionally focused on campaigns designed to stimulate consumption, "demarketing is the aspect of marketing that deals with discouraging customers in general or a certain class of customers in particular on either a temporary or a permanent basis" ([11], p. 75). 
Such a tool is of obvious importance in an environmental context, in which conservation and reduction are often preferable from both an environmental and economic perspective. Demarketing also has several advantages over popular alternative policy instruments, such as command and control regulations or pricing mechanisms. Demarketing and awareness raising campaigns effectively shift consumers' demand curves, rather than simply causing consumers to move to a different point along their curves, as price instruments do, or artificially preventing such movements, as use restrictions do. They also do not impose a disproportionate cost burden on the poor, they do not restrict choice, nor do they differentially burden different segments of the population in any way. Furthermore, demarketing tools can be implemented quickly when needed. For these reasons, they may face less resistance both by consumers and policy-makers (e.g., [23-26]).

Despite such advantages, relatively little research has attempted to evaluate the relative effectiveness of different demarketing campaigns. One reason is the difficulty measuring their effectiveness, especially as they are often implemented in combination with other policy measures. The vast majority of studies have used surveys or laboratory experiments to tap into consumers' intentions of responding to demarketing campaigns, although, recently, there are growing efforts to collect and analyze data on actual behavior and response, including in various environmental contexts. The relatively limited studies of objective consequences following demarketing poses a limitation on our understanding of such practices because of the subjective nature of self-reports and the often weak correlation between consumers' reported attitudes or intentions and their actual behavior [26]. Further, some of the studies that did collect objective, "hard" data on actual consumer behavior through natural experiments (e.g., [24,27]) cannot firmly conclude that the demarketing effect they find is fully attributed to the campaign studied, as they could not control for various intervening factors that could play a significant role in influencing consumer behavior, such as simultaneously launched campaigns, various policy interventions, or other exogenous changes during the period studied. Finally, most demarketing studies focus on short-term interventions and the long-term effect of such campaigns is unclear [24].

\subsection{The Language of Pro-Social Messages}

Research evaluating language effects of pro-social messages has brought to our attention not only the importance of what the messages say, but also how they say it. In particular, the effects of using more and less assertive tones in encouraging pro-social behavior have been investigated in various studies (e.g., $[16,18])$, which have discovered that when an environmental issue is important to the public, campaigns implementing assertive messages, such as "Use only what you need" (Denver 2011 water campaign), are more effective than campaigns that employ more gentle messaging, such as "Please consider using only what you need".

\subsection{The Effectiveness of Assertive and Suggestive Language in Water Conservation}

The consumption of basic goods is different from the consumption of non-basic goods in many aspects, such as consumer populations, consumer's mood, amount spent, etc. Therefore, discouraging the use of non-basic goods (e.g., cigarettes or soda) is different from encouraging the public to give up a basic need, such as water. Assertiveness emphasizes the urgency of the matter at hand and, therefore, when an issue is important, assertive messages may tend to be more effective in encouraging pro-social behavior [16]. However, previous research has also shown that, in many cases, forceful, assertive phrasing may be detrimental to the promotion of pro-social behavior (e.g., [28-31]). We suggest that this is especially true in the case when the behavior concerned with reduction or giving up a basic resource, since the linguistic meaning of assertive phrasing implies that the addressee has no way for refusal [18]. Since assertive phrasing emphasizes a restriction on freedom of choice, we posited that it may not be the most effective communication choice when the issue at hand is a basic need such as water. We, therefore, expected a suggestively phrased water conservation campaign to decrease water consumption to a greater degree than an assertively-phrased campaign. 


\section{Methodology—Controlled Field Experiment}

\subsection{Study Sample}

This study involved a controlled field experiment designed to evaluate the relative effectiveness of different demarketing messages, specifically an "assertive" message versus a suggestive one. The experiment was conducted in the city of Petach Tikva, in Israel. Israel is a semi-arid country that has long since utilized all of its naturally occurring renewable freshwater resources and in which policy-makers have routinely promoted a range of both supply and demand management strategies, including public awareness campaigns to deal with shortages [32]. Petach Tikvah is a middle class town with a population of about 200,000 at the time of the experiment. The town is located in the most populous region of the country, (it is part of the Tel Aviv metropolitan area) and, therefore, represents, as much as possible, a "typical" cross-section of the population. The town hosts the second-largest industrial sector in Israel, including a large portion of hi-tech and biopharmaceutical companies and a base for many communications firms. The study was conducted over the dry season (water consumption was monitored between March and October), during a drought year, when water usage is usually especially high.

The experiment consisted of mailings calling for water conservation. We identified a sample of 1500 households in a neighborhood with relatively homogenous socio-economic characteristics. In order to test the relative impacts of the different types of demarketing messages, we randomly assigned 500 of the households to receive messages with an assertive tone ("You must save water!") and 500 to receive messages with a suggestive tone ("It is worthwhile to save water"), while 500 households serving as a control group received no message.

\subsection{Methodology}

The intervention was executed in three stages, using two types of media. The first stage involved sending an enveloped personally addressed postcard containing only the message and the logo of the local water utility. The second stage involved including the message printed on the regular water bill. The third stage was a replication of the first stage. There was a three week break between the first and second mailings, and a one week break between the second and third mailings. Thus, the whole experimental intervention lasted less than a month. We obtained daily water consumption rates at the household level from the water utility company for a period starting in March, two and half months prior to the first mailing and ending four months after the third mailing, a total of 31 weeks. These time specifications were dictated by Petah Tikva utility and were, therefore, not determined solely by the requirements of the experiment.

One of the major problems in evaluating demarketing and other awareness raising campaigns is that they are often run concurrently with other policy instruments. This was the case during the period in which this study was undertaken, during which Israel was suffering from a multiyear drought and was implementing both price changes and a widely viewed national water conservation campaign. The experiment run for this study controlled for this by conducting a difference-in-difference analysis between consumption by the two intervention groups and the control group, thus isolating the impact of other potentially confounding variables.

Following similar studies evaluating consumption habits over time using panel data (e.g., $[4,9,33,34])$ we ran separate fixed effects regressions, which control for time-invariant variables that may affect household consumption, such as number of residents, income, etc. The regressions were run according to Equation (1) below:

$$
\text { Consumption }_{i t}=\beta_{0}+\beta_{1} \text { Treatment }_{i}+\beta_{2 t} \sum_{t=1}^{n} \text { Time }_{t}+\beta_{3 t} \sum_{t=1}^{n} \text { Time }_{t} \times \text { Treatment }_{i}+u_{i t}
$$

Consumption = average daily household consumption during the period in question; 
Treatment $=$ dummy variable indicating whether or not the household received the message and what type of message, suggestive or assertive;

Time $=$ dummy variables indicating the time period in question;

Time $\times$ Treatment $=$ interaction variables for different time periods and whether or not the household received a message;

$\beta=$ parameters to be estimated;

$\mathrm{u}=$ error term, clustered by household

$i=$ household identifier;

$t=$ time period; and

$n=$ total number of time periods.

Consumption data were aggregated into weekly averages of daily consumption in order to account for periodicity in water use. Separate regressions were run comparing households of each of the two types of campaigns to the control group, while dropping households receiving the other type of message.

\section{Analysis and Results}

\subsection{Descriptive Data}

Water consumption data was collected for 1500 households, however, some observations were dropped from the sample because of faulty meters, attrition (moving or going on extended vacations), returned mail, etc. As a result, the effective number of households included in the final sample analyzed totaled 1399 observations.

Figure 1 presents a seven day running mean of daily water consumption (measured in cubic meters $\left(\mathrm{m}^{3}\right)$ per day). A running mean was used to smooth the data, as actual consumption on a given day is somewhat stochastic. Average daily consumption for the period prior to the first mailing shows no differences between households receiving mailings and those used as controls. However, following the mailings, consumption in households not receiving either message grew significantly, while the change in consumption in households receiving either message appears much less dramatic. The rise (and subsequent fall) in water consumption by the control group is due to rising early summer temperatures, followed by declining late summer and early fall temperatures. This seems to indicate that the treatments seem to have moderated peaks in consumption.

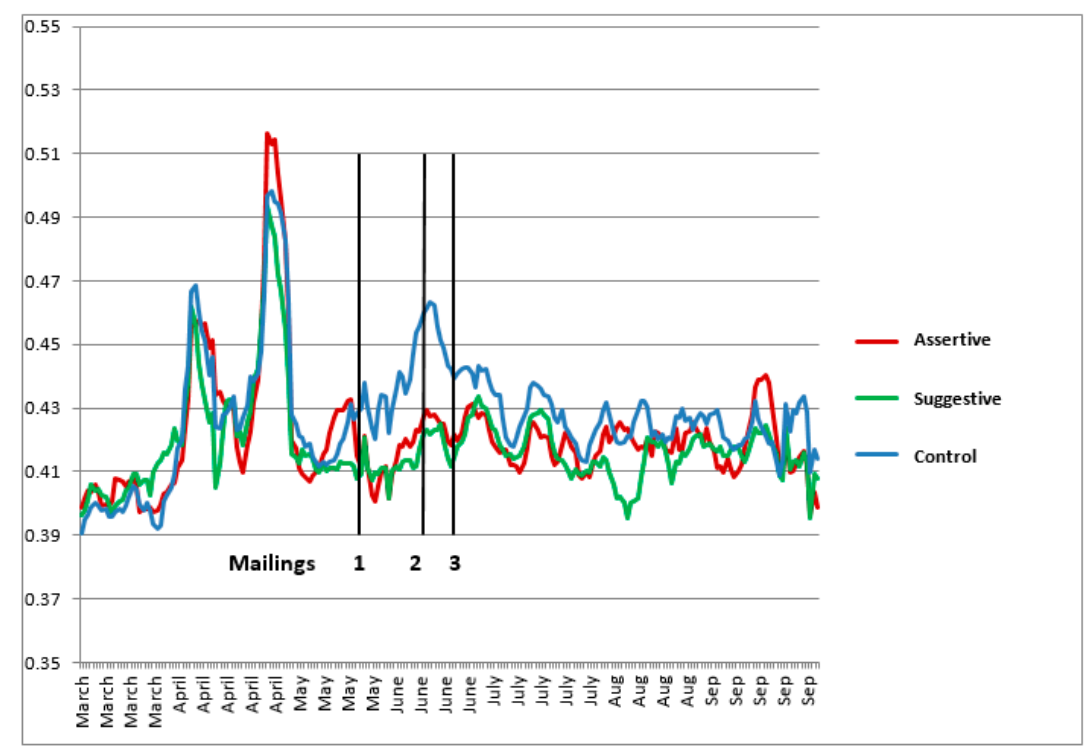

Figure 1. Average household consumption by type of treatment—seven-day running average (cubic meters per day). 


\subsection{Estimated Model Regression Results}

Average daily consumption for weeks 1-4 (March) was used as a base time period in all regressions, thus, results are relative to consumption during this period. Regressions were run both by comparing weekly averages of daily consumption and by collapsing data into biweekly time periods for all periods other than the base period and the periods immediately prior to, during, and immediately following the treatments. For purposes of conciseness only the latter are shown herein. Regressions run using weekly time periods throughout did not change the results in any significant manner. (Regressions were also run using weekly averages of daily consumption for each of the 31 weeks of data with a time period lag of one period, thus comparing the differences in consumption to the period immediately prior to the one in question, rather than to the period prior to the first stage. Results of these regressions are not included herein for the sake of brevity and readability, but did not change the qualitative conclusions of this study.)

The results of the regressions appear in Table 1. For purposes of brevity, only variable coefficients are shown with statistical significance indicated with asterisks. Values for the constant represent mean daily consumption (in cubic meters) by the control group during the base period (weeks 1-4), as such they do not vary between the regressions as the control group served as the basis for comparison in each. The time period dummy variables represent the mean change in consumption for the control group relative to the base period for the period in question, and also do not vary across regressions. Values for the variable treatment represent the difference in mean daily consumption between treatment and control groups during the base period. The time $\times$ treatment interaction variables indicate average daily consumption of treatment groups relative to the control group during the given time period.

Regression coefficients presented in the first column compare the treatment groups to the control group, without distinguishing between types of treatment. The coefficients on treatment and on the time-treatment interaction variables prior to week 12 - the first week following the first mailing —are not statistically significant, indicating that the control and treatment groups did not differ in terms of consumption prior to the initial mailings. Beginning with week 12, however, the treatment households consumed significantly less $(p<0.012)$. This trend of reduced consumption remained throughout the period of analysis. It was statistically significant for five weeks (weeks 12-16).

In evaluating each type of message, observations receiving the other message were dropped from the sample in order to isolate the comparison with the control group. These results are shown in the second and third regression columns. Both types of demarketing messages were somewhat successful in reducing consumption relative to the control group. Although both the graph in Figure 1 and the coefficients on the interaction variables seem to indicate that both types of campaigns had a similar impact (i.e., lower consumption rates relative to the control households for the period immediately following campaign initiation), consumption among the suggestive message group was statistically significantly lower than the control group for a total of seven weeks (weeks 12-16, and weeks 22-23), while among the assertive message group it was statistically different from the control for only two of the weeks (weeks 13 and 15). Additionally, for all time periods in which there was any statistically different consumption rate, the size of the coefficient (and, thus, the reduction in water consumed) was greater for the suggestive group than the assertive one. Thus, as predicted, the suggestive message was more effective than the assertive one both in terms of the size (quantity of water conserved) and the duration (number of weeks statistically different from the control group) of the impact.

Using the coefficients from the regression results, we calculated the amount of water savings due to the campaign. Taking only the differences in consumption for weeks 12 through 16, on average, treatment households consumed $6.9 \%$ less water than control households during the five-week period. Households receiving the suggestive message consumed 7.6\%, less water than control households, while those receiving the assertive one consumed $6.1 \%$ less. The amount saved by household receiving a suggestive message amounted to 1.2 cubic meters per household for the five week period. At the time of the study, Israel had 2,139,300 households [35]. Had all households responded as did those receiving the suggestive messages, Israel would have conserved nearly 2.3 million cubic meters of 
water during the period in question, roughly half a percent of the annual household consumption [36]. This estimate is likely a lower-bound one, as the experiment was done at a time when a national conservation campaign was already in place. Thus, the results are in addition to reductions from this nationwide campaign.

Table 1. Regression results for mean daily consumption $\left(\mathrm{m}^{3}\right)$.

\begin{tabular}{|c|c|c|c|c|}
\hline & Variable & $\begin{array}{l}\text { Control and Treatment } \\
\text { Groups (Both) }\end{array}$ & Control and Suggestive Groups & $\begin{array}{l}\text { Control and } \\
\text { Assertive Groups }\end{array}$ \\
\hline $\begin{array}{l}\text { Consumption during } \\
\text { baseline period }\end{array}$ & Constant (weeks 1-4) & & $0.400^{* * *}$ & \\
\hline \multirow{17}{*}{ Time Period Dummies } & weeks 5-6 & & $0.046^{* * *}$ & \\
\hline & weeks $7-8$ & & $0.045^{* * *}$ & \\
\hline & weeks 9-10 & & $0.040^{* * *}$ & \\
\hline & week 11 & & 0.016 & \\
\hline & week 12 & & 0.030 ** & \\
\hline & week 13 & & $0.034^{* * *}$ & \\
\hline & week 14 & & $0.039 * * *$ & \\
\hline & week 15 & & $0.061 * * *$ & \\
\hline & week 16 & & $0.041^{* * *}$ & \\
\hline & week 17 & & $0.042 * * *$ & \\
\hline & weeks $18-19$ & & $0.029 * *$ & \\
\hline & weeks 20-21 & & $0.021^{*}$ & \\
\hline & weeks 22-23 & & $0.025^{\text {** }}$ & \\
\hline & weeks $24-25$ & & $0.025^{*}$ & \\
\hline & weeks $26-27$ & & $0.025^{*}$ & \\
\hline & weeks 28-29 & & 0.020 ** & \\
\hline & weeks $30-31$ & & 0.024 ** & \\
\hline $\begin{array}{l}\text { Additional consumption } \\
\text { for treatment groups } \\
\text { during baseline period }\end{array}$ & Treatment & 0.006 & 0.007 & 0.004 \\
\hline \multirow{17}{*}{$\begin{array}{l}\text { Time Period-Treatment } \\
\text { Interaction Dummies }\end{array}$} & weeks $5-6$ *T & -0.012 & -0.019 * & -0.005 \\
\hline & weeks $7-8 * \mathrm{~T}$ & -0.005 & -0.006 & -0.004 \\
\hline & weeks $9-10 * \mathrm{~T}$ & -0.015 & -0.020 & -0.009 \\
\hline & week 11 *T & -0.001 & -0.012 & -0.010 \\
\hline & week $12 * \mathrm{~T}$ & $-0.025^{*}$ & $-0.028^{* *}$ & -0.023 \\
\hline & week $13 * \mathrm{~T}$ & $-0.028^{* *}$ & $-0.030^{* *}$ & $-0.026^{*}$ \\
\hline & week 14 *T & $-0.029^{* *}$ & $-0.033^{* *}$ & -0.025 \\
\hline & week 15 * $\mathrm{T}$ & $-0.041^{* *}$ & $-0.045^{* *}$ & $-0.037^{* *}$ \\
\hline & week $16{ }^{*} \mathrm{~T}$ & $-0.027^{*}$ & $-0.030 *$ & -0.025 \\
\hline & week $17{ }^{*} \mathrm{~T}$ & -0.018 & -0.018 & -0.017 \\
\hline & weeks $18-19 * \mathrm{~T}$ & -0.014 & -0.015 & -0.012 \\
\hline & weeks $20-21$ * $\mathrm{T}$ & -0.014 & -0.015 & -0.015 \\
\hline & weeks $22-23 * \mathrm{~T}$ & -0.017 & $-0.027^{*}$ & -0.007 \\
\hline & weeks $24-25$ * T & -0.012 & -0.015 & -0.009 \\
\hline & weeks $26-27{ }^{*} \mathrm{~T}$ & -0.013 & -0.013 & -0.013 \\
\hline & weeks $28-29 * \mathrm{~T}$ & -0.004 & -0.010 & -0.002 \\
\hline & weeks $30-31$ * $\mathrm{T}$ & -0.020 & -0.019 & -0.021 \\
\hline No. of Observations & & 43,369 & 28,954 & 28,737 \\
\hline No. of Households & & 1399 & 934 & 927 \\
\hline
\end{tabular}

Notes: $* * * * *$, and $*$ indicate significant at $1 \%, 5 \%$, and $10 \%$ levels, respectively, based on robust standard errors clustered by household.

\section{Discussion}

The effectiveness of non-price policies such as campaigns to encourage residential water conservation is often unclear. An important question in research is, therefore, what is an optimal way of encouraging residential water conservation?

This paper presents the results of a demarketing intervention designed to reduce residential water consumption. The longitudinal controlled field experiment revealed the relative effectiveness of two types of demarketing messages: an assertive and a suggestive one. While assertive language is more 
prevalent in environmental campaigns, our prediction was that, since water is a basic product, and since assertive language implies restriction of freedom, residents receiving the assertive messages will be less compliant with the call to conserve water, compared with residents receiving the suggestive phrasing.

Using only a very basic message, both assertive and suggestive types of messages yielded reduced consumption levels relative to a control group; however, the suggestive messages were more effective both in terms of magnitude and duration of impact. This is in line with much of the previous literature in marketing communication (e.g., [30,31]). We suggest that these results were due to the freedom restricting character of assertive language, which can be harmful for campaigns that discourage the use of basic resources, such as water. The campaign's effectiveness was, however, of limited duration, a finding similar to others (e.g., $[6,10,13,37]$ ) and it is unclear if continuation of the campaign would have resulted in continued effectiveness. This study has various limitations that might suggest future research opportunities. First, in this research we studied the actual behavior of consumers, but not their motivations and attitudes. While a growing number of researchers recommend studying actual behavior of consumers, this approach has its weaknesses in our context. For instance, we cannot know from the given data if consumers understood the messages as they were intended, as well as how many residents actually noticed the messages. We also were not able to verify that the reasons for the greater effectiveness of suggestive phrases was due to their less restrictive linguistic manner. Other studies have noted that differing motivations for water conservation impact behavior (e.g., [34]). As such, further research may be valuable here, complementing behavioral data with data based on surveys, which will generate deeper insights into the mechanism driving the behavior of consumers.

Secondly, the study was conducted in a specific country and a single conservation context. While in terms of socio-economic development, Israel is similar to many other developed countries and water scarcity is a global environmental concern, the specific nature of the case might limit the general applicability of the findings. This is especially relevant to our claim that water is a basic resource. Our experiment was undertaken during a time of drought in a water scarce country. Other studies have found that conservation increases when water is scarce and the public value of the savings is greatest [38]. It may be the case, for example, that in areas of water abundance we will not find difference between assertive and suggestive phrasing of water conservation campaigns. Our experiment may need further validation via additional similar experiments in other locations, covering different climates, seasons, and socio-economic characteristics. It might be useful, therefore, to conduct cross-country research on demarketing for different environmental resources and additional consumer groups.

Thirdly, the types of messages used were extremely simple. While this implies that even simple campaigns can have an impact, more sophisticated messages may have different effects.

Finally, although the effects of the campaign were measured over a period of three months after its termination, the campaign itself lasted for only four weeks, and there were only three instances of sending a message. As marketing communication's persuasion effects naturally tend to decline over time [39], a study involving a more substantial and longitudinal campaign can support or dispute the results of this paper.

\section{Conclusions}

Water conservation is an increasingly important objective for water utilities and other suppliers. Among the wide range of options that exist for achieving such goals, increasing public awareness by means of conservation campaigns have several advantages, including low costs, minimal political and public opposition, and the ability to implement quickly. Measuring the effectiveness of such campaigns can be challenging, especially as they are often run concomitantly with other conservation measures, such as use restrictions and price adjustments. As noted above, of the existing research on this topic, much has found that such campaigns can be a cost-effective measure, at least in the short to medium term. Most of this research, however, has not evaluated the importance of the specific language used in such campaigns 
This research finds that the type of language used does indeed appear to influence consumer behavior and provides support for the prediction that suggestively-phrased campaigns are more effective than assertively-phrased campaigns in the reduction of water consumption. This may stem from the fact that water is a basic need that may require special attention when phrasing conservation campaigns. Thus, as the saying "still waters run deep" implies, when the goal is to reduce consumption of such a basic need as residential water, a more subtle, gentle phrasing seems to be more successful.

Acknowledgments: The authors would like to thank the Meitav water and sewage utility for access to water consumption data.

Author Contributions: Ann Kronrod, Amir Grinstein and Udi Nisan conceived and designed the experiment; David Katz and Udi Nisan analyzed the data; and David Katz and Ann Kronrod wrote the introduction, literature review and discussion with input from Amir Grinstein and Udi Nisan.

Conflicts of Interest: The authors declare no conflicts of interest.

\section{References}

1. House-Peters, L.A.; Chang, H. Urban water demand modeling: Review of concepts, methods, and organizing principles. Water Resour. Res. 2001, 47, W05401. [CrossRef]

2. Abrahamse, W.; Steg, L.; Vlek, C.; Rothengatter, T. A review of intervention studies aimed at household energy conservation. J. Environ. Psychol. 2005, 25, 273-291. [CrossRef]

3. Abroms, L.C.; Maibach, E.W. The effectiveness of mass communication to change public behavior. Annu. Rev. Public Health 2008, 29, 219-234. [CrossRef] [PubMed]

4. Allcott, H. Social norms and energy conservation. J. Public Econ. 2011, 95, 1082-1095. [CrossRef]

5. Peattie, K.; Peattie, S. Social marketing: A pathway to consumption reduction? J. Bus. Res. 2009, 62, 260-268. [CrossRef]

6. Michelsen, A.M.; McGuckin, J.T.; Stumpf, D. Nonprice water conservation programs as a demand management tool. J. Am. Water Resour. Assoc. 1999, 35, 593-602. [CrossRef]

7. Renwick, M.E.; Green, R.D. Do residential water demand side management policies measure up? An analysis of eight California water agencies. J. Environ. Econ. Manag. 2000, 40, 37-55. [CrossRef]

8. Syme, G.J.; Nancarrow, B.E.; Seligman, C. The evaluation of information campaigns to promote voluntary household water conservation. Eval. Rev. 2000, 24, 539-578. [CrossRef]

9. Ferraro, P.J.; Price, M.K. Using nonpecuniary strategies to influence behavior: evidence from a large-scale field experiment. Rev. Econ. Stat. 2013, 95, 64-73. [CrossRef]

10. Saurí, D. Water conservation: theory and evidence in urban areas of the developed world. Annu. Rev. Environ. Resour. 2013, 38, 227-248. [CrossRef]

11. Kotler, P.; Levy, S. Demarketing, yes, demarketing. Harv. Bus. Rev. 1971, 79, 74-80.

12. Olmstead, S.; Stavins, R. Comparing price and non-price approaches to urban water conservation. Water Resour. Res. 2009, 45, W04301. [CrossRef]

13. Reynaud, A. Assessing the impact of price and non-price policies on residential water demand: A case study in Wisconsin. Int. J. Water Resour. Dev. 2012, 29, 415-433. [CrossRef]

14. Katz, D.; Grinstein, A.; Kronrod, A.; Nisan, U. Evaluating the effectiveness of water conservation campaigns: Combining experimental and field methods. J. Environ. Manag. 2016, 180, 335-343. [CrossRef] [PubMed]

15. Kesternich, M.; Reif, C.; Rübbelke, D. Recent Trends in Behavioral Environmental Economics. Environ. Resour. Econ. 2017, 67, 403-411. [CrossRef]

16. Grinstein, A.; Kronrod, A. Does Sparing the Rod Spoil the Child? How Praising, Scolding, and Assertive Tone can Encourage Pro-Social Behavior. J. Mark. Res. 2016, 53, 433-441. [CrossRef]

17. Corral-Verdugo, V.; Frias-Armenta, M.; Perez-Urias, F.; Orduna-Cabrera, V.; Espinoza-Gallego, N. Residential water consumption, motivation for conserving water and the continuing tragedy of the commons. Environ. Manag. 2002, 30, 527-535. [CrossRef]

18. Kronrod, A.; Grinstein, A.; Wathieu, L. Go green! Should environmental messages be so assertive? J. Mark. 2012, 76, 95-102. [CrossRef]

19. Bernedo, M.; Ferraro, P.J.; Price, M. The Persistent Impacts of Norm-Based Messaging and Their Implications for Water Conservation. J. Consum. Policy 2014, 37, 437-452. [CrossRef] 
20. Otaki, Y.; Ueda, K.; Sakura, O. Effects of feedback about community water consumption on residential water conservation. J. Clean. Prod. 2017, 143, 719-730. [CrossRef]

21. Schultz, P.; Messina, A.; Tronu, G.; Limas, E.F.; Gupta, R.; Estrada, M. Personalized Normative Feedback and the Moderating Role of Personal Norms: A Field Experiment to Reduce Residential Water Consumption. Environ. Behav. 2014, 48, 686-710. [CrossRef]

22. Kronrod, A.; Grinstein, A.; Wathieu, L. Enjoy! Assertive Language and Compliance in Hedonic Contexts. J. Consum. Res. 2012, 39, 51-61. [CrossRef]

23. Dietz, T.; Stern, P. New Tools for Environmental Protection: Education Information and Voluntary Measures; National Academy Press: Washington, DC, USA, 2002.

24. Grinstein, A.; Nisan, U. Demarketing, minorities, and national attachment. J. Mark. 2009, 73, $105-122$. [CrossRef]

25. Rothschild, M. Carrots, sticks, and promises: A conceptual framework for the management of public health and social issue behaviors. J. Mark. 1999, 63, 24-37. [CrossRef]

26. Wall, A. Government demarketing: Different approaches and mixed messages. Eur. J. Mark. 2005, 39, 421-427. [CrossRef]

27. Kallis, G.; Ray, I.; Fulton, J.; McMahon, J.E. Public Versus Private: Does It Matter for Water Conservation? Insights from California. Environ. Manag. 2010, 45, 177-191. [CrossRef] [PubMed]

28. Schlegelmilch, B.; Bohlen, G.; Diamantopoulos, A. The Link between Green Purchasing Decisions and Measures of Environmental Consciousness. Eur. J. Mark. 1996, 30, 35-55. [CrossRef]

29. Deutsch, J.; Liebermann, Y. Effects of a public advertising campaign on consumer behavior in a demarketing situation. Int. J. Mark. Res. 1985, 2, 287-296. [CrossRef]

30. Dillard, J.P.; Lijiang, S. On the nature of reactance and its role in persuasive health communication. Commun. Monogr. 2005, 72, 144-168. [CrossRef]

31. Quick, B.L.; Considine, J.R. Examining the use of forceful language when designing exercise persuasive messages for adults: A test of conceptualizing reactance arousal as a two-step process. Health Commun. 2008, 23, 483-491. [CrossRef] [PubMed]

32. Katz, D. Policies for water demand management in Israel. In Water Policy in Israel; Becker, N., Ed.; Springer: Dordrecht, Netherlands, 2013; pp. 147-163.

33. Wang, Y.-D.; Song, J.-S.; Byrne, J.; Yun, S.-J. Evaluating the persistence of residential water conservation: A 1992-1997 panel study of a water utility program in Delaware. J. Am. Water Resour. Assoc. 1999, 35, 1269-1276. [CrossRef]

34. Maas, A.; Goemans, C.; Manning, D.; Kroll, S.; Arabi, M.; Rodriguez-McGoffin, M. Evaluating the Effect of Conservation Motivations on Residential Water Demand. J. Environ. Manag. 2017, 196, 394-401. [CrossRef] [PubMed]

35. Israeli Central Bureau of Statistics. Statistical Abstract of Israel 2011; Israeli Central Bureau of Statistics: Jerusalem, Israeli, 2012.

36. Israeli Water Authority. Water Consumption by Category 1996-2013. 2014. Available online: http:/ / www.water.gov.il/Hebrew / ProfessionalInfoAndData/Allocation-Consumption-andproduction/ 20133/1996-2013.pdf (accessed on 22 April 2014).

37. Kenney, D.S.; Goemans, C.; Klein, R.; Lowrey, J.; Reidy, K. Residential Water Demand Management: Lessons from Aurora, Colorado. J. Am. Water Resour. Assoc. 2008, 44, 192-207. [CrossRef]

38. Aisbett, E.; Steinhauser, R. Maintaining the Common Pool: Voluntary Water Conservation in Response to Varying Scarcity. Environ. Resour. Econ. 2014, 59, 167-185. [CrossRef]

39. Wood, L. Short-term effects of advertising: Some well-established empirical law-like patterns. J. Advert. Res. 2009, 49, 186-192. [CrossRef]

(C) 2018 by the authors. Licensee MDPI, Basel, Switzerland. This article is an open access article distributed under the terms and conditions of the Creative Commons Attribution (CC BY) license (http:/ / creativecommons.org/licenses/by/4.0/). 